\title{
RE-SIGNIFICAÇÃO DA IDENTIDADE CULTURAL DOS TERÊNA DE EKERUÁ: UMA ABORDAGEM DA PRODUÇÃO CULTURAL SUBALTERNA
}

Sérgio Ricardo Losnak

Professor, Geógrafo Cultural, especialista em Gestão de Projetos Culturais e Eventos pelo CELACC (ECA/ USP)

\section{Resumo}

Este artigo traça a trajetória dos índios Terêna, desde sua origem na região do Chaco à fixação de um de seus grupos na Aldeia de Ekeruá, localizada na Reserva Indígena de Araribá, Centro Oeste Paulista. Os constantes contatos com seus parentes indígenas e com os não indígenas, durante seus deslocamentos em terras brasileiras são mostrados como processos de assimilação, aculturação, re-significação e desterritorialização dos quais foram sujeitos durante estes últimos dois séculos. É neste contexto mais difuso proporcionado pela nova ordem globalizante que se verifica ações marcantes dos indígenas de Ekeruá na reconstrução de sua identidade, na recuperação de seus saberes e fazeres tradicionais, e ao mesmo tempo a transformação de sua produção cultural em produto. Por meio da identificação da diferença e da desigualdade dos quais estes cidadãos brasileiros estão sujeitos é que a pesquisa de campo identificou resultados concretos de empoderamento proporcionados por sua produção cultural rica e diversa, pelo reconhecimento de sua própria identidade re-significada e pelas novas possibilidades de desenvolvimento sustentável do grupo.

Palavras- chave: Povo Terêna; produção cultural subalterna; Etnografia; desterritorialização; re-significação cultural; identidade.

\begin{abstract}
The aim of this work is to draw the trajectory of Terena Indians, since their origin in Chaco region up to the housing of one of their groups in Ekeruá Village, located in Araribá Reservation, in the centralwestern region of São Paulo State. Their daily contacts with Indian and non-Indian relatives during their removal through Brazilian lands are evidenced as assimilation, acculturation, resignificance and deterritorialization processes from which they were exposed to during the last two centuries. It was in this most diffuse context provided by a globalizing new order that one verifies remarkable action of Ekeruás in the reconstruction of their identity, in the recovering of their own knowledge and traditional trades, and, at the same time, in the transformation of their own cultural production into products. This field research, through difference and inequality identification from which these native Brazilian citizens are exposed to, has identified real results of empowerment provided by their different and rich cultural production, by recognizing their own resignified identity and by new possibilities of sustainable development of the group.
\end{abstract}

Keywords: Subaltern Cultural Production; Ethnography; deterritorialization; cultural resignificance.

\section{Resumen}

El objetivo de este trabajo ha sido identificar la trayectoria de Indios Terena, desde su origen en la región del Chaco, hasta el poblamiento de uno de sus grupos en la Vivienda de Ekeruá, ubicada en la Reserva Indígena de Araribá, en la parte centro-occidental del Estado de São Paulo. Los contactos diarios con sus parientes indígenas y no indígenas, durante sus desplazamientos por tierras brasileñas son evidenciados como procesos de asimilación, aculturación, resignificación y desplazamiento de los cuales han sido expuestos durante los últimos dos siglos. Es en este contexto muy difuso, propuesto por un nuevo orden globalizante, que se puede verificar acciones marcantes de los indígenas de Ekeruá en la reconstrucción de su propia identidad, en la recuperación de sus conocimientos y artesanías tradicionales, $\mathrm{y}$, al mismo tiempo, en la transformación de su producción cultural en producto. A través de la identificación de la diferencia y de la desigualdad a las que estos ciudadanos nativos brasileños están expuestos es que esta investigación de campo ha identificado resultados concretos de emancipación promovidos por su producción cultural abundante y diversa, por el reconocimiento de su propia identidad resignificada y por nuevas posibilidades de desarrollo sustentable por el grupo.

Palabras clave: Producción cultural subalterna; Etnografía; desplazamiento; resignificación cultural. 


\section{RE-SIGNIFICAÇÃODAIDENTIDADECULTURALDOSTERÊNA DE EKERUÁ: UMA ABORDAGEM DA PRODUÇÃO CULTURAL SUBALTERNA}

\section{Introdução}

A contemporaneidade é marcada, sobretudo pelas transformações provocadas por sucessivas ondas globais que atuam principalmente por meio dos fenômenos políticos, econômicos, culturais, sociais e ambientais, reconfigurando constantemente diferentes espaços, tempos, indivíduos e sociedades.

Dentro do contexto mais recente da globalização o capital financeiro, viabiliza freneticamente novos tipos de mercado, institui padrões de vida baseados nas possibilidades do acúmulo e do consumo, estabelecendo assim a condição do "ter" com nova forma de poder e reconfigurando as situações de inclusão ou exclusão dos indivíduos tanto na organização social urbana como na rural. A desigualdade é uma das características mais marcante deste novo modelo, pois vem adquirindo de forma gradual a situação de conseqüência aceitável e até mesmo necessária dentro da lógica instituída pelo capital. Com significativa tolerância, sociedades e indivíduos convivem com a desigualdade sem a condição prática da indignação.

A cultura, sob a égide da globalização, ganha novas formas e significados, se dinamiza nas redefinições e na criação das identidades múltiplas dos indivíduos, diante das influências exercidas pelos diferentes agentes como, por exemplo, os "midias", o mercado cultural, as políticas públicas, privadas e as novas tecnologias. Traz-se para a cultura um sentido mais materialista tanto da concepção como da produção, desarticulando os modos do criar e fazer já instituídos em seus longos processos históricos e perdendo a característica singular e de essência do seu determinado grupo. Estabelece-se uma nova lógica, um novo modelo de produção cultural, que atende as necessidades e exigências do novo mercado, se tornando na contemporaneidade um dos seguimentos capitalista que mais se desenvolvem na economia global.

A cultura, conforme Canclini (2005) se desterritorializa por conseqüência de sua hibridação. É mediante as misturas e mestiçagens ocasionadas entre os diferentes povos e etnias, associadas às possibilidades proporcionadas pelas novas tecnologias que de forma mais intensa e rápida, estimula o conhecimento, as relação entre os indivíduos e suas manifestações culturais. Independente da localização geográfica e do distanciamento físico, os lugares se tornam próximos, permitindo a construção de novos códigos individuais e coletivos, novas formas de relacionamento e interação entre os indivíduos.

Assim, a cultura pode ser compreendida como agente de aproximação e reconhecimento tolerante das diferenças. O saber da existência e o contato com as diversidades múltiplas ampliam o espectro de visão sobre as particularidades do mundo e de como os grupos humanos se comportam e conduzem no seu complexo processo de organização social. A partir destes pressupostos, mesmo desterritorializada, a cul- 


\section{RE-SIGNIFICAÇÃODAIDENTIDADECULTURALDOSTERÊNA DE EKERUÁ: UMA ABORDAGEM DA PRODUÇÃO CULTURAL SUBALTERNA}

tura constrói a possibilidade de valorização do próprio indivíduo e de seu grupo, seja pela sua história, tradição, modos de criar e fazer, ou pelo entendimento de sua própria diferença para com os demais, além da marca trazida pela sua singularidade e identidade.

É dentro da perspectiva da economia desigual e da cultura da diferença que este artigo se propõe, por meio de uma visão sociológica, etnológica, geográfica cultural e da filosofia da práxis, diagnosticar e identificar a produção cultural da etnia indígena Terêna na atualidade. O método dialético irá proporcionar reflexões sobre os saberes e fazeres deste povo e de como estes mecanismos podem recriar uma inter-relação com sua própria cultura tradicional, se tornando meios para reconstrução permanente de sua identidade coletiva e na formação material e imaterial de seu patrimônio histórico cultural.

Subsidiado por depoimentos que proporcionaram calorosas conversas, ora ocorridas debaixo da sombra de jatobás, ora em moradias simples e confortáveis ou ainda em festividades coletivas e de reuniões da governança local, este artigo, tem o propósito de mostrar a produção cultural do artesanato, dos jogos cênicos, da língua materna e da memória oral dos indígenas da etnia Terêna, que se encontram aldeados em Ekeruá, em área da Reserva Indígena de Araribá, localizada no município de Avaí, região do Centro Oeste Paulista.

\section{O povo Terêna}

Tratar e compreender a produção cultural contemporânea Terêna passa pelo reconhecimento dos intensos e constantes processos de aculturação, assimilação e deslocamento a que foram submetidos, principalmente pela interferência dos povos hegemônicos do ocidente, os espanhóis e portugueses, durante a ocupação e exploração colonialista na América Latina, como também, mais recentemente pela última onda globalizante, onde o colonialismo se da pela influência principalmente do capital.

Estas interferências constantes no processo evolutivo das sociedades originária da América Latina se configuram como mecanismos de extermínio, tirania, exclusão e cerceamento dos direitos mínimos necessários para a sobrevivência natural destes povos, deixando marcas significativas em sua formação cultural.

Os Terêna são originários do $\mathrm{Chaco}^{1}$, região onde uma grande diversidade de grupos e subgrupos étnicos indígenas se relacionavam por meio de processos de dominação e de interdependência. As análises e referências preconizadas por autores clássicos e por cronistas em seus trabalhos de campo sobre os indígenas que ali viviam, de uma forma geral, indicam que não existe uma unanimidade quanto à divisão 


\title{
RE-SIGNIFICAÇÃODAIDENTIDADECULTURALDOSTERÊNA DE EKERUÁ: UMA ABORDAGEM DA PRODUÇÃO CULTURAL SUBALTERNA
}

e classificação dos diferentes grupos, mas é consenso sobre a teoria da existência de um grande grupo chamado Aruák, que se divide em dois subgrupos bem diferentes por suas práticas culturais e pelo desenvolvimento de suas técnicas, chamados Chané e Guanás, conforme aponta Carvalho.

\begin{abstract}
"As "nações" indígenas eram muito distintas cultural e "lingüisticamente". Dentre as mais importantes destacavam-se: a Chiriguana (Guarani), com população composta de 40 a 50 mil pessoas; Mbayá, com 3 a 4 mil, dividida em sete ou nove tribos, muito temida pelos Espanhóis e por outros grupos tribais; Guaná, a mais pacífica e dócil, com cerca de 30 mil índios, dividida em sete grupos: Layana ou Chaná; Terêna ou Etelena, com dois “pueblos”; Echoaldi; Neguecagatemi; Equinikinao, também com dois "pueblos”. As demais eram: Mataguaya, Vilela, Lule, Macobi, Abipon, Lengua, Payaguá, Zamuca e Yacure. (CARVALHO, 1979, p. 24)
\end{abstract}

Os Terêna são os últimos remanescentes dos Guanás e tem o Aruák como língua materna, eram considerados pacíficos e exímios agricultores, utilizavam o sistema de roças que permitia obtenção de alimentos durante o ano todo. Esta foi a principal característica que os colocaram em situação de subordinação/integração com os seus parentes Mbayá-Guaicurú, povo nômade e guerreiro, que detinham a técnica de uso de metal como adorno e da utilização de cavalos como arma de guerra, logo após a introdução destes animais na América pelos Espanhóis ${ }^{2}$. As relações intertribais não se restringiam somente por meio dos conflitos e dominação, mas também por alianças estabelecidas por meio do matrimônio.

Esta complexa relação de interdependência entre os grupos pode ser caracterizada mais como uma união para suplantar as deficiências particulares encontradas pelas etnias, do que uma submissão simples imposta pelo domínio da força, da técnica ou mesmo da cultura.

Oliveira (1976) classifica como simbiótica as assimilações dos saberes e fazeres culturais dos Terêna com seus parentes indígenas. Posteriormente estas relações se expandiram para com os colonizadores e mais recentemente com as sociedades não indígenas das cidades e do campo.

\footnotetext{
"Pois essa estreita interação - simbiótica - até certo ponto pode ser generalizada para o universo Guaná, caracterizando todo um período que as relações, entre as partes representativas de ambos os grupos, assumiram formas sistemáticas e contínuas, e que resultaram num processo de aculturação inter-tribal, sem cuja consideração se torna impossível compreender a cultura Terêna (Guaná) tradicional.” (OLIVEIRA, 1997, p.36)
}

A produção cultural Terêna atual é composta pela diversidade de significados, representações e técnicas que foram sendo assimiladas e apropriadas através do tempo, de acordo com as relações estabelecidas com os índios e os não índios. Compreende-las requer partir do pressuposto de que tais manifestações foram sendo construídas, reconstruídas e principalmente perdidas durante sua evolução histórica. 
Com o processo de genocídio implantado na região pelos colonizadores, os nativos da região do Chaco passaram por volta dos séculos XVIII e XIX a intensificar seus deslocamentos. Os Terêna seguiram no sentido sul pelo Rio Paraguai em direção ao atual Estado do Mato Grosso do Sul. Segundo Castelnau apud Carvalho (1979) a migração maciça iniciou-se por volta de 1845 .

A ocupação das terras brasileiras pelos índios Guanás não foi nada tranqüila. Carvalho (1976) aponta três importantes movimentos que os colocaram em completa situação de exclusão e desterritorialização. $O$ primeiro movimento se refere à expansão pastoril no centro oeste, sudeste e sul do país. O segundo se deu em virtude de um complexo fluxo humano gerado pela Guerra do Paraguai. Neste momento, os Terêna se aliaram ao Império pela promessa de serem reconhecidos como povo brasileiro e de terem seus territórios definidos legalmente. $\mathrm{O}$ terceiro movimento advém da construção da Estrada de Ferro Noroeste do Brasil, que trazia como símbolo o "eldorado" - caminho para o oeste -, que viabilizou uma robusta rede de comunicação com o oeste do Brasil. Partindo de Bauru - S.P., com interligação ao porto de Santos - S.P., chegando até Corumbá - M.S. Tratava-se de um projeto estratégico Latino Americano, visando à interligação do Oceano Atlântico com o Oceano Pacífico.

Os constantes deslocamentos dos Terêna em terras brasileiras impossibilitaram a suas práticas tradicionais de instituição de lugares, conforme se pode relacionar com os conceitos de Claval (2007).

A instituição de territórios, espaços e lugares devem-se em virtude de uma relação íntima um elo estreito, assimilado pelo grupo diante do seu significado. Não há sociedade sem espaço para lhe servir suporte, ou seja, todo individuo necessita apropriar-se do espaço, de alguma forma demarcá-lo e denominá-lo, ter uma referência espacial para cultuar seus mortos, localizar-se, para que assim possa construir sua identidade cultural.

A falta de referência espacial para a construção de uma sociedade remodelada de acordo com a sua nova realidade, fez com que os Terêna cada vez mais se integrassem aos meios culturais dos não indígenas. Sua desterritorialização proporcionou novas condições de organização social, como a condição de indígenas não aldeiados, que passaram a viver nas periferias das cidades, a de colonos que se dedicavam ao trabalho nas fazendas e mais tarde a situação de tutelados por parte do Estado.

Com a criação SPI - Serviço de Proteção Indígena, em 1910, pelo governo brasileiro, a política indigenista introduzida pelo Marechal Cândido Rondon - descendente de índio - direcionou-se para a criação de Reservas, onde os mesmos foram confinados e controlados como patrimônio federal, experimentando um novo modelo de organização sociocultural, passando de sua organização social associativa para 


\section{RE-SIGNIFICAÇÃODAIDENTIDADECULTURALDOSTERÊNA DE EKERUÁ: UMA ABORDAGEM DA PRODUÇÃO CULTURAL SUBALTERNA}

o modelo de núcleo familiar.

Sendo criada em 1913, a Reserva Indígena de Araribá somente recebeu os primeiros Terêna em 1932, foram trazidos do Mato Grosso do Sul para repovoamento da Reserva, logo após a gripe espanhola ter quase dizimado a população Guarani e Caingangue que ali viviam.

\footnotetext{
"No Araribá os Terêna começaram a chegar em grupos familiais, a partir de 1932". Primeiramente ai aportaram 21 indivíduos, entre adultos e menores, sendo 11 do sexo masculino e 10 do sexo feminino. Foram trazidos para dedicarem-se ao plantio e colheita do café, atividades que os Guarani não haviam mostrado aptidão ou interesse. Tempo depois, 12 deles, 6 de cada sexo regressaram ao Mato Grosso. Posteriormente houve novas chegadas...” (DINIZ, 1976, p. 46)
}

Atualmente, a Reserva de Araribá esta dividida em quatro aldeias, com sistema de governança indígena específico para cada uma delas, possui 144 residências para uma população total de 557 indígenas, sendo que estão divididos nas aldeias da seguinte forma: aldeia Ekeruá 146 moradores; aldeia Nimuendajú 74 moradores; Kopenoty 200 moradores e Tereguá 107 moradores. $^{3}$

\section{Aldeia Ekeruá}

Ekeruá foi formada recentemente, no ano de 2002, após uma divisão política sob a questão da terra e gestão indígena da Reserva. Basicamente é constituída por índios Terêna, porém é importante considerar que os Terêna tradicionalmente apresentam características exogâmicas, sendo possível constatar a existência de matrimônios entre índios Terêna e Guarani dentro da aldeia de Ekeruá, conforme depoimento do professor indígena David.

\footnotetext{
"O artesanato eu aprendi com minha mãe, minha mãe fazia, como meu avo falou, ele se chama Francisco e é Guarani, minha mãe é Guarani e meu pai é Terêna, o que chamamos de Tereguá, Terêna com Guarani. Eu me intitulo Terêna e não Guarani, porque cresci na Aldeia Kopenoti e lá só vivem os Terêna, eu cresci na cultura Terêna." (DAVID, depoimento gravado em 05/07/09 na aldeia de Ekeruá).
}

Ekeruá conta com 146 moradores fixos, sendo 78 do sexo masculino e 68 do sexo feminino, a faixa etária de maior concentração esta em torno dos 10 a 19 anos, ou seja, população altamente jovem, e acima dos 60 anos ainda vivem na aldeia 9 pessoas. ${ }^{4}$

O contingente humano na aldeia esta dividido em 37 residências construídas em alvenaria no formato de um grande círculo. $\mathrm{O}$ espaço central da aldeia é destinado as ações coletivas, composto por um belo campo de futebol gramado, um de seus lados existe uma estrutura coberta para realização de atividades diversas, sala de aula, capela com características herdadas da religião católica, banheiros, rancho circular de 


\section{RE-SIGNIFICAÇÃODAIDENTIDADECULTURALDOSTERÊNA DE EKERUÁ: UMA ABORDAGEM DA PRODUÇÃO CULTURAL SUBALTERNA}

médio porte de eucalipto e sapé, um pequeno depósito geral construído em madeira e uma escola que encontra-se em estágio final de construção. Do outro lado do campo, pode-se observar uma igreja da Assembléia de Deus, construída em alvenaria bem maior que a citada.

\section{Relações de produção e trabalho}

As principais atividades econômicas desenvolvidas pelos habitantes de Ekeruá se dão basicamente pela venda da força de trabalho ou pela produção diversa que atenda as necessidades do mercado urbano próximo. As atividades de produção tradicionais indígenas como por exemplo o artesanato se colocam na dimensão secundária no quesito geração de renda. $\mathrm{O}$ processo de vida indígena tradicional passa a ser reconfigurado diante das demandas externas da aldeia, e do que Milton Santos classifica de "motor único", onde a produção e as técnicas se mundializam, gerando a mais-valia-universal, porém a participação neste processo produtivo e da apropriação destes resultados são altamente excludente, principalmente para os subalternos organizados em sociedades particulares frágeis e pouco associativas como a dos Terêna.

Neste contexto de mais-valia-universal, a produção econômica de Ekeruá é incipiente para geração de uma estabilidade econômica digna para seus moradores, trazendo diversos conflitos e provocando situações de exclusão e miserabilidade. Podemos classificar em quatro tipos as práticas experimentadas pelos moradores da aldeia. O primeiro e principal tipo identificado, esta ligada ao uso da terra da Reserva. Em maior dimensão esta o cultivo dos tubérculos, mandioca e batata doce, que são comercializados diretamente pelos seus produtores no Ceasa de Bauru. Em menor escala estão a produção leiteira, de mel e da agricultura de subsistência praticada em pequenas roças com características de trabalho familiar, onde cada grupo toma para si a terra que tem a capacidade de fazê-la produzir, assumindo todas as despesas inerentes a produção e a força de trabalho.

O segundo tipo se configura por meio da venda da força de trabalho para diferentes fins externos a aldeia. Muitos índios se dedicam as atividades de baixa complexidade em fazendas próximas, conforme depoimento do Cacique Jasone, esta relação de trabalho está configurada por meio de pagamento de diária, ou seja, se ganha exatamente o dia que se trabalha, não existindo vínculo ou qualquer tipo de beneficio trabalhista. Este tipo de relação também foi identificado, por volta do início do século $\mathrm{XX}^{5}$, nesta mesma Reserva, quando o próprio SPI, órgão do Estado, responsável pela administração da Reserva, contratavam índios para serviços diversos sob o mesmo modelo de diária. Índios e índias com mais formação e estudo trabalham nas cidades próximas em atividades domésticas, no comércio, em pequenas empresas ou indústrias, e principalmente em serviços que exige pouca qualificação. Nestas atividades a relação de trabalho se dá de forma contratual obedecendo a legislação vigente. 


\section{RE-SIGNIFICAÇÃODAIDENTIDADECULTURALDOSTERÊNA DE EKERUÁ: UMA ABORDAGEM DA PRODUÇÃO CULTURAL SUBALTERNA}

O terceiro tipo de relação de trabalho praticado pelos indígenas de Ekeruá se dá de forma legal e formal, porém com característica particular de relação direta com as diferentes instancia de Estado, por meio dos organismos criados para tutelar e outros para garantir a integridade étnica e cultural destes indivíduos. A FUNAI, FUNASA, Secretaria de Educação e Saúde do Estado de São Paulo e do município de Avaí e órgãos ligados ao Governo Federal, se tornaram grandes empregadores de mão de obra indígena, apesar de terem em seus quadros a maioria não indígena, principalmente nos postos de comando.

O quarto e último tipo é caracterizado pela produção e comercialização cultural tendo como referência as particularidades étnicas culturais tradicionais dos indígenas Terêna. Basicamente esta atividade busca a complementação de renda por meio do artesanato e se coloca hierarquicamente atrás de todas as outras atividades praticadas pelos moradores da aldeia, carrega ainda outras características originárias, que é sua prática em momentos de ócio, técnicas repassadas por gerações e matéria prima retirada de meio natural, porém na atualidade agregaram-se as perspectivas de mercado e não mais tende somente a atender as necessidades do cotidiano e da religiosidade.

\section{A reconstrução da identidade pela cultura}

São poucos os registros encontrados que tratam da produção cultural mais tradicional dos Terêna, mas o que se sabe é que esta cumpria as necessidades relacionadas ao cotidiano, aos rituais, aos cerimoniais e a decoração diversa ${ }^{6}$. Com o processo de aculturação intenso a que foram submetidos, o criar e fazer absorveram novos valores, significados e sentidos através do tempo, alterando-se de acordo com os espaços que cada grupo instituiu como lugar e com as relações estabelecidas com grupos humanos diferentes.

A dualidade provocada pela motivação da produção cultural tradicional e da assimilada, traz ao grupo um conflito identitário, a principio criou-se um distanciamento do tradicional, provocando uma ausência de sentido dos seus fazeres culturais, posteriormente com a necessidade de geração de renda e de auto afirmação, a produção cultural adquiriu novas perspectivas. A Dança da Chuva praticada pelos Terêna de Ekeruá na atualidade se torna um bom exemplo, pois seu objetivo é exclusivamente estabelecer uma comunicação direta com o público por meio do espetáculo. A comunicação com o divino, em que seus antepassados praticavam por meio dessa dança deixou de existir. Para pedir que a chuva chegue, e proporcione fartura na roça, foram incorporadas novas formas de comunicação com o divino, agora proporcionadas pelo cristianismo.

A necessidade do desenvolvimento de técnicas para manutenção da vida, diante 


\section{RE-SIGNIFICAÇÃODAIDENTIDADECULTURALDOSTERÊNA DE EKERUÁ: UMA ABORDAGEM DA PRODUÇÃO CULTURAL SUBALTERNA}

do meio, fez com que os indígenas desenvolvessem utensílios, adornos e ferramentas, com objetivos muito bem definidos, hoje estes mesmos objetos, são classificados como artesanato com características utilitárias ou de adorno. Já as danças, jogos e os mitos estão relacionados as relações coletivas e com o divino, que simbolicamente dão novo sentido à vida.

Para os Indígenas, a vida para ser mantida e ter sentido exige determinada relação com o divino, requer o exercício de reconhecer e estabelecer uma relação próxima, instituindo um sistema de comunicação por meio de diferentes símbolos e códigos, que se diferenciam de acordo com as características de cada etnia e com o seu processo histórico. Esta relação de presença intensa do divino na produção cultural os aproxima e os faz sentirem aceitos e protegidos pelas divindades no mundo concreto para que possam seguir o caminhar evolutivo

É pela perspectiva de produção cultural que se pode verificar que este grupo Terêna adquire formas de reconstrução permanente de sua identidade. Ferreira (2008) afirma que o processo de colonização e controle psicológico visa exterminar a identidade originária e substituí-la por outra, com os mesmos significados do dominador. Assim a produção cultural, como o artesanato, a língua e as manifestações cênicas são os signos que congregam os aldeiados, que os remete aos significados de suas origens e proporcionam à possibilidade de construção de projetos de resistência coletiva a subjugação e da imposição assimilativa de uma identidade exógena.

\footnotetext{
"Na construção da identidade cultural (nacional), cristaliza-se a capacidade de um povo de determinar seu próprio destino, seu porvir individual, de classe ou nação. Nisso consiste a identidade. A identidade de um sujeito individual ou coletivo é o compasso, a bússola que o orienta através da história. É por isso que qualquer projeto de dominação utiliza-se do controle psicológico do submetido. A destruição da identidade é o primeiro passo em qualquer tentativa de dominação: a colonização da personalidade." (FERREIRA, 2008 P. 59)
}

\section{Produção cultural em Ekeruá}

A produção cultural Terêna de Ekeruá se mostra espontânea e lentamente renasce como forma de resistência, emergindo de dentro para fora de sua sociedade, pelas ações conscientes de suas lideranças e pela implantação de uma política emancipadora pelos professores indígenas, juntos trabalham no estímulo pela consciência de suas diferenças étnicas e pela manutenção de sua cultura tradicional.

A língua materna, o artesanato, as danças, os jogos cênicos e a memória oral são as manifestações culturais que mais se revelam na comunidade de Ekeruá, sendo que a comunicação através da linguagem originária é a relação que mais os aproxima de sua cultura originária. 


\section{RE-SIGNIFICAÇÃODAIDENTIDADECULTURALDOSTERÊNA DE EKERUÁ: UMA ABORDAGEM DA PRODUÇÃO CULTURAL SUBALTERNA}

Aquelas que geram produtos são disponibilizadas como forma de geração de renda e as demais contribuem para divulgação das características étnicas, em festividades na aldeia, eventos e feiras em cidades próximas. Estas produções provocam uma das poucas oportunidades de interação e trocas entre a população local, são momentos de trabalho coletivo onde se efetivam as práticas culturais, exercendo o planejamento, a execução, difusão e as noções de comércio. Na dança a estrutura de trabalho familiar é trocada pelo coletivo, remetendo a origem mais tradicional de seus antepassados.

Parte das características e técnicas de produção dos Terêna conseguiram se manter durante seu longo processo histórico, sua transmissão foi sendo viabilizada de geração em geração pela memória oral e pelo exercício da prática.

Duas das mais idosas índias de Ekeruá, as irmãs Ingrácia e Joana, matriarcas do fazer da cerâmica na aldeia, relatam processo de transmissão da técnica e indicam que quando este processo se deu a atividade já objetivava o mercado.

\footnotetext{
"Aprendemos a fazer a cerâmica com a finada minha mãe, só nos duas, ia crescendo e ia chamando a gente, via ela fazendo, nos duas acompanha, a maioria trabalha na aldeia, o trabalho de todo mundo era fazer cerâmica, cada uma fazia em sua casa, as mulheres da comunidade mulheres fazia, não sei se fazem ainda, todas elas trabalhavam moravam na aldeia de Cachoeirinha MS. Ai senta no chão pega o barro e vai fazendo e não brinca minha mãe não deixava brincar, não brinca com a mãe, não podia brincar, respeita a mãe quando a mãe chama tem senta e faze. Senta faz um pouco um dia e continua no outro." (Ingrácia entrevista realizada em 05/07/ 09 na aldeia de Ekeruá)
}

A Cerâmica é o artesanato que mais identifica a cultura Terêna, por sua coloração avermelhada e pela pintura monocromática. Seus produtos basicamente se dualizam em utensílios domésticos, como vasos, cuias, panelas, moringas e por objetos de decoração, principalmente animais e aves. É uma atividade praticada exclusivamente pelas mulheres diferentemente de outros tipos de artesanato, que se constata a presença de homens.

Os demais tipos de artesanato são produzidos por grupos familiares, é comum todos os membros de uma mesma família se dedicarem a este trabalho, como é o caso da família de dona Elisângela.

\footnotetext{
"Eu acabei ensinando a todo mundo daqui de casa, porque estas coisas a gente vai passando para a família, meu pai ensinou nós, porque eu via ele fazendo, ai eu casei com Terêna, mais os Terêna mechem mais com cerâmica, os colares de semente eles não meche, mais como ele comigo foi aprendendo eu fui passando, aprendeu trançar, até aprendeu o trançado de guaimbe e com isso meu filho foi também apreendendo e todos já sabem da família." (Elisângla,entrevista realizada em 05/07/09 na aldeia de Ekeruá)
}

A produção dos demais tipos de artesanato pode ser dividida em adornos 


\section{RE-SIGNIFICAÇÃODAIDENTIDADECULTURALDOSTERÊNA DE EKERUÁ: UMA ABORDAGEM DA PRODUÇÃO CULTURAL SUBALTERNA}

como colar, brincos, braceletes, cintos entre outros, como também diversos instrumentos, alguns musicais como flauta de bambu e chocalhos e outros de caça, como arco e flecha, lanças e zarabatana. Muitos dos adornos são característicos da cultura indígena, outros mais ocidentalizados. Toda a produção é praticamente feita manualmente sem o auxílio de ferramentas ou maquinas. Grande parte da matéria prima utilizada é aquela encontrada na própria aldeia, cipó, sementes de diferentes espécies, bambu e penas, a diversidade da produção esta definida pela obtenção de matéria prima.

\footnotetext{
"Meu pai fala que os índios Guarani viam os desenhos das cobras entendeu, vê que é quase igual, via o desenho que tinha na cobra e fazia igual, vê esse aqui também tem o desenho da cobra, essa e de outra cobra mais tem da jibóia que é assim, tipo de balãozinho, então antigamente os índios fazia igual das cobras meu pai fez e a gente vai passando pros outros. A gente acaba tirando as idéias da própria natureza, dos animais." (Elisângela,entrevista realizada em 05/07/09 na aldeia de Ekeruá)
}

As atividades cênicas praticadas em Ekeruá envolvem toda a comunidade, de crianças a idosos, de forma coletiva e divertida se pintam, utilizam adornos e vestimentas semelhantes as usadas por seus antepassados. A dança do Bate-Pau é estritamente masculina, em fila dupla os homens se confrontam simbolizando um momento de guerra entre duas tribos inimigas, segundo explicações do Cacique Jasone. A Dança da Chuva é praticada somente por mulheres e esta relacionada à fertilidade. A encenação de contos ligados à mitologia Terêna é algo que foi apropriado dos contadores de historias do passado e a transmissão se deu através da oralidade. Segundo David os pajés Terêna tinham o papel de manter viva a imaginação e a mitologia, reuniam as crianças nas noites de luar no centro da aldeia, contando e representando diversas historias. $\mathrm{Na}$ atualidade esta atividade não é mais desenvolvida pelo pajé, os professores indígenas assumiram este papel e deram um caráter mais teatralizado para a transmissão de seus mitos e das historias de seu povo.

A língua materna dos Terêna o Aruák, com o passar do tempo se tornou uma língua secundária praticada em Ekeruá, utilizada pelos índios mais velhos principalmente em ambientes mais reservados, como dentro de casa e em pequenos grupos. O português então se tornara a língua principal, era a única ensinada na escola local e utilizada nas diferentes formas de comunicação, o que acabou levando os Terêna a um significativo distanciamento da língua materna, conforme relata a Secretária de Educação de Avaí, Ondina Zapater, "as crianças não falavam mais a língua materna". Foi no ano de 2001, que a Rede Municipal de Ensino de Avaí introduziu nas escolas da Reserva, a figura do indígena como auxiliar do professor titular, trabalhavam juntos em sala de aula com objetivo de introduzir o ensino da Língua materna e no resgate da linguagem. Quando da estadualização das escolas indígenas em 2003 pelo Governo do Estado de São Paulo, a Secretaria de Educação, em parceria com a Faculdade de Educação da Universidade de São Paulo, iniciou um processo de 


\section{RE-SIGNIFICAÇÃODAIDENTIDADECULTURALDOSTERÊNA DE EKERUÁ: UMA ABORDAGEM DA PRODUÇÃO CULTURAL SUBALTERNA}

formação de professores indígenas da própria Reserva. Atualmente somente existem professores indígenas nas escolas da Reserva, o que provocou a efetivação pedagógica de ensino bilíngüe.

Com a formação dos professores indígenas os alunos aprendem à língua materna e o português. Essa metodologia de ensino bilíngüe tem causado certo empoderamento aos jovens diante dos não índios por dominarem uma segunda língua, se sentem diferentes pela capacidade da comunicação e pela ligação mais íntima com sua identidade cultural. É possível verificar este fortalecimento na aldeia quando se vê crianças conversando e brincando na língua materna, que, de acordo com o professor David, a escola atende as orientações dos PCNs - Parâmetros Curriculares Nacionais e funciona da seguinte forma.

\footnotetext{
"Na escola formal da aldeia atende até a oitava série, trabalham 7 professores todos são indígenas da própria aldeia. E esta dividida em 3 eixos, um da linguagem de códigos; que trabalham a língua portuguesa, Terêna e inglês também, artes, o outro que eu dou que é ciências e matemática e o terceiro, história e geografia. Na escola tem oficinas todas culturais, nosso idioma, estórias do nosso passado a escola funciona por ciclo 1,2 e 3 . O ciclo 1 é o $1^{\circ}, 2^{\circ}$ e $3^{\circ}$ ano, o ciclo 2 é o $4^{\circ}$, $5^{\circ}$ e $6^{\circ}$ ano e o ciclo 3 é $7^{\circ}, 8^{\circ}$ e $9^{\circ}$ ano. Temos hoje 58 alunos." (David, entrevista realizada em 05/070/09 na aldeia de Ekeruá)
}

Diante de todo o processo de pesquisa de campo que acabou proporcionando uma relativa intimidade com diversos moradores da aldeia, e principalmente com as conversas informais sem o constrangedor "gravador" é que foi possível constatar que existe determinada consciência da situação de submissão social do qual o grupo esta sujeito. Foi possível perceber principalmente entre os índios mais politizados o entendimento de que abrir a aldeia para que a sociedade conheça suas diferenças culturais será uma forma de auto-afirmação de sua identidade e de uma grande possibilidade de se construir novas perspectivas de trabalho por meio do turismo, tendo como principal atrativo suas manifestações culturais.

A comunidade de Ekeruá vem buscando novas perspectivas de vida por meio de suas diferenças, suas características originárias tem provocado um determinado empoderamento cultural. Essa recente situação é possível de ser identificada quando de sua participação do projeto "Caminhos Turísticos do Centro Oeste Paulista", que congrega dez municípios da região na viabilização das potencialidades locais, buscando o fomento do turismo.

Diante desta nova perspectiva, a produção cultural da aldeia começa a ser vista pelos moradores como algo que pode proporcionar novas possibilidades. O estímulo a se expressar artisticamente, tendo como referencia suas raízes, ganha maior dimensão e aceitação principalmente dos mais jovens, permitindo que a auto-afirmação de sua cultura, diminua os conflitos de identidade com a sociedade não indígena. 


\section{Considerações finais}

Isolados da maior concentração de seu grupo étnico no Brasil e distantes de suas terras de origem, os Terêna de Ekeruá se tornaram um testemunho da sobrevivência e resistência no interior do Estado de São Paulo. Tutelados pelo Estado e segregados pela sociedade, a exemplo de seus antepassados, continuam sua luta pela manutenção de sua essência tradicional de vida, de sua cultura e de suas tradições. O processo de interferência inter-ética se intensificou após o contato com o branco, mas verifica-se que estas experiências de miscigenação e assimilação da cultura já se mostravam presentes com outras etnias indígenas, sendo bem aceitas pelos diferentes grupos Terêna, porém essas influências eram menos impactantes do que aquelas causadas pelas sociedades não indígenas.

Com a migração para a Reserva de Araribá, os Terêna iniciam um novo e significativo processo de desterritorialização, provocando uma instabilidade étnica e cultural no percurso de reconstrução de sua identidade. Nota-se que após 70 anos da chegada dos Terêna em Araribá, com a criação da aldeia de Ekeruá, surge o sentimento e ações concretas de construção de novas perspectivas e oportunidades, tanto de apropriação do espaço regional, como no sentido de valorização coletiva de suas tradições culturais.

As diferentes atividades coletivas introduzidas no cotidiano da nova aldeia, em virtude da condução da gestão política da governança local, têm estimulado o entendimento dos moradores a respeito de suas diferenças étnicas e de como utilizar esta particularidade como forma de potencializar as ações produtivas do grupo e dos indivíduos.

A produção cultural de Ekeruá, fomentada de forma crescente tem provocado um olhar mais particular de si próprio, orientados pelos professores indígenas da escola local, estão canalizando ações na viabilização de um Centro de Cultura Indígena, na própria aldeia, que leva o nome de Ekipaê. Na língua Terêna, Ekipaê significa Ema, ave com grande presença em sua mitologia. Este projeto idealizado pela própria comunidade indígena, se tornará um espaço de formação para a população local e de difusão cultural dos Terêna para os visitantes da aldeia. Este complexo cultural irá ser formado por estruturas físicas típicas, como a casa da reza, da farinha, moradia, trilhas na mata, ou seja, uma representação originária do modo de vida tradicional dos Terêna, algo que atualmente não pode ser encontrado na aldeia.

O Centro de Cultura Kipaê se estabelece pela relação direta dos índios, principalmente dos jovens e daqueles que praticam atividades culturais, com as particularidades da vivência do fazer e do criar da tradicional cultura Terêna. Assim tende a se transformar em um local receptivo de turistas, criando um fluxo de visitas para 


\section{RE-SIGNIFICAÇÃODAIDENTIDADECULTURALDOSTERÊNA DE EKERUÁ: UMA ABORDAGEM DA PRODUÇÃO CULTURAL SUBALTERNA}

divulgação de sua cultura e do incremento do comércio de sua produção.

Atualmente, quando visitantes adentram a aldeia, principalmente jovens de idade escolar, tendem a reconhecer uma realidade indígena muito próxima a da deles, pois é comum ver carros, casas de alvenaria, campo de futebol, indivíduos com roupas de marcas conhecidas, ou seja, a idéia simbólica que se tem dos indígenas é muito diferente daquela encontrada na aldeia.

Então o que se esta propondo em Ekeruá é oferecer a possibilidade de conhecer a realidade indígena atual, como também sua dimensão originária e tradicional, sem deixar a dimensão de contextualização do conflito existente entre o originário e o contemporâneo real, para que se provoque no individuo externo, a realidade indígena, o entendimento sobre o processo de re-significação cultural os quais foram submetidos e consequentemente provocar o reconhecimento de suas diferenças e da dívida histórica existente pára com os originários destas terras.

Neste contexto de reconstrução de identidade e da perspectiva de transformação de forma mais intensa da produção cultural em produto, a proposta local deve se colocar em profunda reflexão das perspectivas futuras na qual estará sujeita, surgindo a necessidade de estreitamento das relações com as produções culturais originárias, das possibilidades de viabilização de novos mecanismos de pesquisa que estabeleça relação direta com o imaginário da população local, de forma a entender as assimilações que podem interferir negativamente em sua produção cultural atual. Buscar mecanismos de acesso público a recursos para viabilização de seus projetos, por meio dos seus recursos humanos existentes, estabelecendo parcerias com agentes e entidades culturais na busca pelo fomento local. Assim muitos questionamentos podem porvir desta situação dialética e complexa, como por exemplo.

Como produzir artesanato em escala comercial, provendo as necessidades do mercado sem distanciar ou perder as técnicas originárias? Como assimilar novas técnicas e contextualizando com a realidade imediata e presente? Como manter a prática bilíngüe e principalmente o uso cotidiano da língua Terêna na aldeia? Sustentar a manutenção de um sistema educacional bilíngüe de qualidade, a exemplo de escolas hegemônicas com a mesma prática, possibilitará a emancipação étnica do povo Terêna? De fato, as danças praticadas hoje refletem as atividades culturais do povo Terêna antes do contato com os brancos, ou foi uma forma assimilada para reproduzir determinadas relações inter-tribais em sua fase originária? Quais são as peças artesanais utilitárias ou de adorno que sobreviveu às interferências e adaptações das diferentes gerações? Como capacitar os indígenas para elaboração de projetos para captação de recursos e editais púbicos.

Muito ainda resta a conhecer sobre o grupo étnico Terêna, mas o que se cons- 
tata nesta aproximação pouco estreita proporcionada por esta pesquisa de campo é a grande relevância pela busca constante da integridade e da conquista de um lugar ao sol desta sociedade frágil e ao mesmo tempo poderosa por meio de suas particularidades culturais.

\section{Referências bibliográficas}

AZEVEDO, Fernando. "Um trem corre para o oeste". São Paulo: Martins, 1950. BOSI, Alfredo. "Cultura brasileira: Temas e situações". 4. ed. São Paulo: Editora Ática, 2006.

CANCLINI, Nestor Garcia. "Diferentes, desiguais e desconectados". Rio de Janeiro: UFRJ, 2005.

“As culturas populares no capitalismo”. São Paulo: Brasiliense, 1983.

CARVALHO, Edgard de Assis. "As alternativas dos vencidos: índios Terêna no Estado de São Paulo". Rio de Janeiro: Paz e Terra, 1979.

CASAS, Frei Bartolomé de Las. "O paraíso destruído: a sangrenta história da conquista da América Espanhola". Porto Alegre: L\&PM, 1991.

CHAUI, Marilena. "Cidadania cultural: O direito à cultura”. São Paulo: Fundação Perseu Abramo, 2006.

CLAVAL, Paul. “A geografia cultural”. 3. ed. Florianópolis: UFSC, 2007.

COELHO, Teixeira. "Dicionário crítico de política cultural”. 2. ed. São Paulo: Iluminuras, 1999.

CORREAA, Roberto Lobato; ROSENDAHL, Zeny. "Introdução à geografia cultural". Rio de Janeiro: Bertrand Brasil, 2003.

DINIZ, Edson Soares. "Dependência e destino: Os Guarani e os Terêna do Araribá". Tese de Curso de Livre Docência, na disciplina de Antropologia, da Faculdade de Filosofia, Ciências e Letras de Marília, da Universidade Estadual Paulista - UNESP. Marília: 1976.

FERREIRA, Maria Nazareth. "Globalização e identidade cultural na América Latina”. 2. ed. São Paulo: Centro de Estudos Latino-americano sobre Cultura e Comunicação, Escola de Comunicação e Artes, Universidade de São Paulo, 2008.

"Cultura subalterna e neoliberalismo: A encruzilhada da América Latina". São

Paulo: Centro de Estudos Latino-americano sobre Cultura e Comunicação, Escola de Comunicação e Artes, Universidade de São Paulo, 1997.

"Identidade cultural e turismo emancipador". São Paulo: Centro de Estudos Latino-americano sobre Cultura e Comunicação, Escola de Comunicação e Artes, Universidade de São Paulo, 2005.

IANNI, Octávio. “A era do globalismo”. Rio de Janeiro: Civilização Brasileira, 1996.

MAESTRI, Mário. “Terra do Brasil: A conquista lusitana e o genocídio Tupinambá”. 
São Paulo: Moderna, 1993.

NIETZSCHE, Friedrich Wilhelm. "Humano, demasiado humano: Um livro para espíritos livres". São Paulo: Companhia das Letras, 2005.

NEVES, Correa das. "História da Estrada de Ferro Noroeste do Brasil". Bauru:Tipografias e Livrarias Brasil, 1958.

OLIVEIRA, Roberto Cardoso. "Urbanização e tribalismo: a integração dos índios Terêna numa sociedade de classe". Rio de Janeiro: Zahar, 1968.

. "Do índio ao Bugre: o processo de assimilação dos Terêna". 2. ed. Rio de Janeiro: Francisco Alves, 1976.

ORTIZ, Renato. "Cultura brasileira \& identidade nacional”. 5. ed. São Paulo: Brasiliense, 2006.

REIS, Ana Carla Fonseca. "Economia da cultura e desenvolvimento sustentável: O caleidoscópio da cultura". Barueri: Manole, 2007.

RUBIM, Antônio Albino Canelas; BARBALHO, Alexandre (Orgs.). "Políticas culturais no Brasil”. Salvador: Universidade Federal da Bahia, 2007. (Coleção Cult, 2).

SANTOS, Milton. "Por uma outra globalização do pensamento único à consciência universal”. 15. ed. Rio de Janeiro: Record, 2008.

. "Técnica, espaço, tempo: globalização e meio técnico-científico informacional". 3.ed. São Paulo: Hucitec, 1997.

SCHADEM, Egon. "Leituras de etnologia brasileira". São Paulo: Companhia Editora Nacional, 1976.

SEMERARO, Giovanni. "Gramsci e os novos embates da filosofia da práxis". Aparecida, SP: Idéias e Letras, 2006.

SILVA, Armando Corrêa. "O espaço fora do lugar". 2. ed. São Paulo: Hucitec, 1978.

WILLIAMS, Raymond. “Cultura”. 3. ed. São Paulo: Paz e Terra, 2008.

\section{Notas}

${ }^{1}$ Chaco é uma área geográfica plana de baixa altitude, vegetação predominante de xerófilas, de estações bem definidas, com clima quente e seco, compensado por uma farta hidrografia, situa-se no sul da Bolívia, oeste do Paraguai, norte da Argentina e na parte oeste do Brasil, entre a margem direita dos rios Paraná e Paraguai, de um lado, e o sopé dos Andes do outro.

${ }^{2}$ OLIVEIRA, Roberto Cardoso de. "Do índio ao Bugre: o processo de assimilação dos Terêna". 2. ed. Rio de Janeiro: Francisco Alves, 1976.

${ }^{3}$ Dados relativos a março de 2009, informado pela Assessoria de Saúde Indígena

- Pólo Base Bauru - FUNASA - Fundação Nacional de Saúde

${ }^{4}$ Idem 
RE-SIGNIFICAÇÃODAIDENTIDADECULTURALDOSTERÊNA DE EKERUÁ: UMA ABORDAGEM DA PRODUÇÃO CULTURAL

SUBALTERNA

${ }^{5}$ Dados pesquisados nos Livros Caixa do Serviço de Proteção indígena do ano de 1914, localizados nos arquivos do Centro de Memória de Bauru.

${ }^{6}$ FERREIRA, Maria Nazareth. "Globalização e identidade cultural na América Latina”. 2. ed. São Paulo: Centro de Estudos Latino-americano sobre Cultura e Comunicação, 2008. 